\title{
Sleep quality in patients with chronic low back pain
}

\author{
Qualidade do sono de indivíduos com dor lombar crônica
}

\author{
Verônica Leonor França, Micheline Henrique Araújo da Luz Koerich, Guilherme S. Nunes*
}

Universidade do Estado de Santa Catarina (UDESC), Florianópolis, SC, Brazil

\begin{abstract}
Introduction: Sleep performs a restorative function for the body. Medical conditions such as Chronic Low Back Pain (CLBP) may cause sleep changes and impair sleep quality. Objectives: To identify the prevalence of sleep disorders among individuals with CLBP, and investigate whether there is an association between these disorders and perceived functional disability. Materials and methods: This observational, descriptive study was conducted with 51 patients seen at the Clinic of the School of Physical Therapy of Santa Catarina State University. Data were collected through interviews addressing socio-demographic and clinical data, and administration of the Roland-Morris Disability Questionnaire (RMDQ) and Pittsburgh Sleep Quality Index (PSQI). Results: Participants had high levels of functional disability (mean, $16.71 \pm 4.16$ score points). $82.35 \%$ of patients had poor sleep quality (mean, $10.22 \pm 4.84$ score points). The PSQI components with the highest mean scores were: sleep latency and sleep disturbances. There was also a weak association between functional disability and sleep quality (Spearman $=0.31 ; \mathrm{p}=0.025$ ), i.e., the higher the disability, the worse the quality of sleep. Conclusion: We found a high prevalence of sleep disorders among patients with CLBP, and a weak association with the level of perceived disability. It is important to conduct further studies on
\end{abstract}

*VLF: physiotherapist, e-mail: veronica_lf@msn.com MHALK: MSc, e-mail: michelineha@ig.com.br GSN: MSc, e-mail: nunesguilherme@live.com 
the relationship between these factors and sleep quality. Moreover, there is a need for a multidisciplinary approach in the treatment of CLBP, in order to treat sleep disorders and improve patients' quality of life.

Keywords: Low back pain. Sleep. Prevalence.

\section{Resumo}

Introdução: O sono tem ação restauradora no organismo e condições clínicas como a Dor Lombar Crônica (DLC) podem provocar alterações e prejudicar sua qualidade. Objetivos: Identificar a prevalência de distúrbios do sono em indivíduos com DLC e verificar se há a associação destes distúrbios com a incapacidade funcional percebida. Materiais e Métodos: Estudo descritivo observacional, realizado com 51 pacientes da Clínica Escola de Fisioterapia da Universidade do Estado de Santa Catarina. A coleta de dados incluiu entrevista com informações sociodemográficas e clínicas do paciente e aplicação do Questionário Roland-Morris de Incapacidade (QRM) e do Índice de Qualidade do Sono de Pittsburgh (PSQI). Resultados: Os indivíduos pesquisados apresentaram nível alto de incapacidade funcional (média de 16,71 $\pm 4,16$ pontos) e 82,35\% dos pacientes apresentaram má qualidade do sono (média de 10,22 $\pm 4,84$ pontos), sendo os componentes do PSQI com maiores valores médios: "Latência do Sono" e "Distúrbios do sono". Verificou-se também associação fraca entre incapacidade funcional e qualidade do sono (Spearman $=0,31 ; p=0,025$ ), sendo que quanto maior a incapacidade, pior a qualidade do sono. Conclusão: $O$ estudo mostrou alta prevalência de distúrbios do sono nos pacientes com DLC e uma fraca associação com o nível de incapacidade percebido. Ressalta-se a importância de ampliar a investigação sobre a relação entre esses fatores e de uma abordagem multidisciplinar no tratamento da DLC, para que aspectos como os distúrbios do sono possam ser tratados e melhorar a qualidade de vida dos pacientes.

Palavras-chave: Dor Lombar. Sono. Prevalência.

\section{Introduction}

Chronic low back pain (CLBP) can be defined as pain that affects the lumbar, lumbosacral or sacroiliac regions, and lasts for more than three months (1). CLBP is a major cause of work absenteeism, temporary or permanent disability, and even incapacitation, and results in high economic costs for social security systems and health care services $(2,3)$.

Pain is the major complaint of individuals with CLBP and it may negatively affect the quality of life of these patients by limiting their functional capacity and ability to perform activities of daily living and/or work (4). Pain also affects other quality-of-life parameters, such as psychological well-being and sleep. (1) Studies indicate that over $50 \%$ of people with CLBP have sleep-related problems (5 - 8).

Sleep performs a restorative function for the body and, when it becomes ineffective, it can cause significant physiological and psychological changes. In the long term, these changes can also contribute to the emergence of other diseases $(9,10)$. Sleep disorders in people with chronic pain, as in the case of CLBP, cover a wide range of factors and are characterized by complaints of reduced sleep efficiency and sleep duration, increased sleep latency (time to fall asleep), fragmentation of sleep stages, and daytime sleepiness (not feelingrested during the day) $(11,12)$. These disorders have a negative effect on mood, severity of perceived pain, willingness to perform daytime activities, and other quality-of-life aspects $(13,14)$. Moreover, it may also affect patients' recovery by reducing their willingness to participate in rehabilitation programs.

Experimental studies suggest suggest the possibility that the relationship between sleep disturbance and pain might be reciprocal, such that pain disturbs sleep continuity/quality and poor sleep further exacerbates pain (15). Persistent pain may lead to lasting functional changes to the neural systems that regulate both sleep and pain. However, this mechanism is still poorly understood and many aspects still need to be investigated as both conditions ("sleep disorders" and "Chronic Low Back Pain") are considered to be complex and multi-factorial.

Although several recent studies associate sleep disorders with low back pain (LBP) $(8,12,16-18)$, 
and report a poorer overall sleep quality in individuals with LBP, there is still little information on the relationship between sleep quality and level of disability caused by lower back pain $(8,19)$.

Given that the intensity of CLBP varies among individuals, impacting their functional capacity and quality of life in different ways, studies investigating this relationship can contribute to the understanding of the interaction between chronic low back pain and sleep.

Given the above, the aim of this study was to identify the prevalence of sleep disorders among individuals with CLBP, and investigate whether there is an association between these disorders and perceived functional disability.

\section{Methods}

This observational, descriptive study was conducted with 51 patients with CLBP seen at the Clinic of the School of Physical Therapy of Santa Catarina State University. The study project was approved by the Ethics Committee for Research with Human Beings of the College of Health and Sport Science, UDESC (opinion 159.184).

The sample selection started by screening patients' medical records. Inclusion criteria were: age between 30 and 65 years, and main complaint of "low back pain" lasting for more than three months or clinical diagnosis of CLBP. Exclusion criteria were: presence of other musculoskeletal or neurological disorders; diagnosis of depression; and postoperative pain.

After identifying the patients who had CLBP, we contacted them by phone in order to confirm whether they really met the inclusion criteria, and invited those who did to participate in the study. Data were collected through interviews addressing socio-demographic and clinical data, and administration of the Pittsburgh Sleep Quality Index (PSQI) and the Roland-Morris Disability Questionnaire (RMDQ) both validated for use in the Brazilian population. (20) The RMDQ is a common tool used to assess perceived functional disability in people with low back pain. It is a self-administered questionnaire scored on a 24-point scale from (no disability) to 24 (severe disability). In this study we have used 15 points as cut-off (21). Scores lower than 15 have been interpreted as "low level of disability" and scores equal to or greater than 15 were regarded as "high level of disability".

As for the Pittsburgh Sleep Quality Index (PSQI) (22) it is a self-rated 19-item instrument intended to assess sleep quality and sleep disturbance in clinical populations. It yields seven components scores, namely: subjective sleep quality, sleep latency (time to fall asleep), sleep duration, habitual sleep efficiency (ratio of hours slept as compared to hours spent in bed), sleep disturbances, use of sleeping medications, and daytime dysfunction. Each component is given a score ranging from zero to three, and the sum of all components yields a global PSQI score between 0 and 21. The higher the overall score, the poorer the quality of sleep. Scores greater than 5 indicate poor sleep quality.

All instruments were completed by the researchers, who had been trained to collect data for this study. All interviews were conducted at the Clinic of the School of Physical Therapy of Santa Catarina State University (UDESC).

Statistical analysis was performed in two stages. We performed descriptive statistics, including measures of central tendency, frequencies and percentages, mean, variability and standard deviation. The Shapiro-Wilk test was applied to verify the normal distribution of the data. The relationship between "Functional Disability" and "Sleep Quality" was calculated using Spearman's correlation test ( $\mathrm{r}$ ). The significance level was set at $p<0.05$. Correlation strength was classified as follows: low, $\mathrm{r} \leq 0.4$; moderate, $\mathrm{r}=$ 0.4 to 0.5 ; and high, $r \geq 0.5$. (23) Statistical analysis was performed using SPSS (Statistical Package for Social Sciences) version 17.

\section{Results}

$15 \%$ (9) of the 60 individuals contacted to participate in the study did not attend the interview. Hence, the final sample consisted of 51 subjects. Participants' main characteristics are summarized in Table 1.

According to the data in Table 1, the mean age of respondents was 50.63 years $( \pm 8.47)$, and most of them $(63 \%)$ were women. In addition, the leading cause of low back pain were discopathies (82\%). With regard to the professional situation, we found that $49 \%$ of participants were active workers. Homemakers were included in this group. Almost one third of respondents 
(31\%) were away from their professional activities due to chronic low back pain. We also found that participants had very different education levels.

As for the quality of sleep (measured with the PSQI), 82.35\% of patients had a total score greater than 5 (mean, $10.22 \pm 4.84$ ), which indicates poor sleep quality. Higher mean values were were noted for the components of sleep latency (2.02) and sleep disturbances (1.75). The latter was also the component that presented the highest prevalence among patients with altered sleep patterns, followed by the components subjective sleep quality $(92.2 \%)$ and sleep latency (84.3\%). By contrast, the components that presented the lowest prevalences among participants were use of sleeping medication and daytime dysfunction, with means of 1.04 and 1.00, respectively. The mean score achieved by participants in the Roland-Morris Disability Questionnaire was 16.71 (Table 2), indicating high level of disability.

Correlation analysis indicated that functional disability correlated positively with sleep quality $(\mathrm{r}=$ $0.31 ; p=0.025$ ). This correlation was low but linear, suggesting that higher levels of disability may be associated with poorer quality of sleep (Figure 1).

Table 1 - Clinical and socio-demographic characteristics of individuals with chronic low back pain (VAS)

\begin{tabular}{|c|c|c|}
\hline \multicolumn{3}{|l|}{ Variables } \\
\hline \multirow{2}{*}{ Age } & Mean & SD \\
\hline & 50.63 & 8.47 \\
\hline Gender & $n$ & $\%$ \\
\hline Male & 19 & $37 \%$ \\
\hline Female & 32 & $63 \%$ \\
\hline \multicolumn{3}{|l|}{ Time since onset of symptoms } \\
\hline 3 months - 1 year & 24 & $47 \%$ \\
\hline $1-2$ years & 9 & $18 \%$ \\
\hline 2 years or more & 18 & $35 \%$ \\
\hline \multicolumn{3}{|l|}{ Cause } \\
\hline Nonspecific & 4 & $8 \%$ \\
\hline Discopathy & 42 & $82 \%$ \\
\hline Other ${ }^{*}$ & 5 & $10 \%$ \\
\hline Professional situation & n & $\%$ \\
\hline Active & 25 & $49 \%$ \\
\hline Away due to illness & 16 & $31 \%$ \\
\hline Retired & 9 & $18 \%$ \\
\hline Unemployed & 1 & $2 \%$ \\
\hline \multicolumn{3}{|l|}{ Education } \\
\hline Incomplete primary school & 17 & $33 \%$ \\
\hline Complete primary school & 9 & $18 \%$ \\
\hline Incomplete high school & 3 & $6 \%$ \\
\hline High school diploma & 13 & $25 \%$ \\
\hline Incomplete higher education & 2 & $4 \%$ \\
\hline Complete higher education & 7 & $14 \%$ \\
\hline
\end{tabular}

Note: * scoliosis, spondylolysis, osteophytosis. 
Table 2 - Mean PSQI scores, prevalence of individuals with and without changes in PSQI scores, and mean RMDQ scores

\begin{tabular}{|c|c|c|c|c|c|c|}
\hline \multirow[b]{2}{*}{ PSQI components } & \multicolumn{2}{|c|}{$\begin{array}{l}\text { Mean scores } \\
\quad \mathbf{N}=51\end{array}$} & \multicolumn{2}{|c|}{$\begin{array}{c}\mathrm{PSQI} \leq 5 \\
\mathrm{~N}=9\end{array}$} & \multicolumn{2}{|c|}{$\begin{array}{c}\mathrm{PSQI} \geq 5 \\
\mathrm{~N}=41\end{array}$} \\
\hline & Mean & SD & Freq. & $\%$ & Freq. & $\%$ \\
\hline Subjective sleep quality & 1.47 & 0.86 & 4 & 7.8 & 47 & 92.2 \\
\hline Sleep latency & 2.02 & 1.12 & 8 & 15.7 & 43 & 84.3 \\
\hline Sleep duration & 1.55 & 1.19 & 13 & 25.5 & 38 & 74.5 \\
\hline Habitual sleep efficiency & 1.39 & 1.34 & 21 & 41.2 & 30 & 58.8 \\
\hline
\end{tabular}

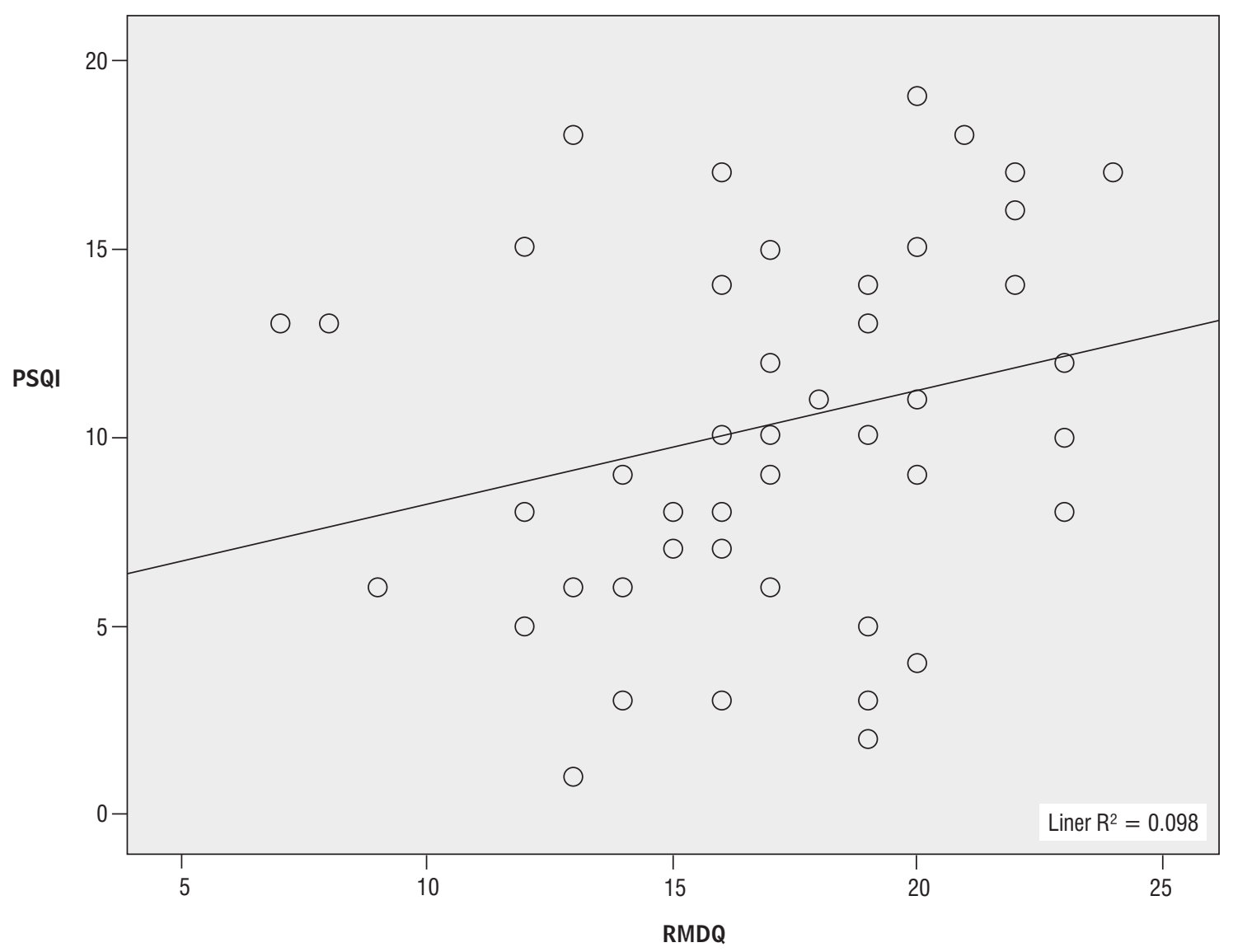

Figure 1 - Association between scores obtained in the Pittsburg Sleep Quality Index (PSQI) and in the Roland-Morris Disability Questionnaire (RMDQ)

Legend: PSQI = Pittsburgh Sleep Quality Index; RMDQ = Roland-Morris Disability Questionnaire

Source: Research data 


\section{Discussion}

Our results confirm a high prevalence of sleep disorders among patients with CLBP, and a weak association with the level of perceived disability. Other studies have not found an association between sleep quality and perceived functional disability, despite the fact that instruments to assess functional capacity are widely used in studies on CLBP.

Most of the 51 individuals who participated in the study were women, as in other previous studies. (6, 8,19 ) The mean age of participants was 50.63 years, which is close to mean age found in other studies with the same population $(6,8,17,19,24)$. In our study, $49 \%$ of participants continued as active workers despite the limitations caused by low back pain. 30\% of patients were away from work due to the disease.

Several studies have found a higher prevalence of sleep disorders in patients with CLBP and most of these studies indicate that more than $50 \%$ of patients have sleep-related problems (16-18). The diversity of instruments and methodological procedures used in these studies, however, make it difficult to compare results across studies. The prevalence found in our study was higher (82.35\%) than that found in other studies, probably due to the higher cutoff point used by other researchers to rank sleep quality. In the study by O'Donoghue (19), which also investigated sleep disturbances, there was also a high prevalence of individuals who scored greater than 5 in the PSQI (86.6\%). This prevalence was much higher than that found in the control group (6.6\%).

The total PSQI score achieved indicates that most respondents have poor sleep quality. This corroborates the results of other studies $(8,17,19)$. The mean PSQI score in our study $(10.22 \pm 4.84)$ was similar to the mean PSQI scores found in other studies that have investigated sleep disturbances in patients with CLBP. The mean scores found in these studies ranged between 10.4 and $10.9(6,8,24)$. Smith (15) suggests that the poor sleep quality found in this population is associated with the persistent and long-lasting pain, wich ends up interfering with sleep, due to the same location in the neural control systems. Thus, pain interferes with sleep and, in turn, sleep disturbances increase pain, thus creating a cycle in which one factor causes or worsens the other (11). Nevertheless, it is believed that other biological (age and gender) and psychosocial (ability of coping with the disease, anxiety, depressive symptoms) factors may also affect the "pain/sleep" interaction, making the understanding of this phenomenon even more complex.

In addition, in the IQSP, the highest scores were noted for the components of sleep latency and sleep disturbances. While the first aspect (sleep latency) is related to difficulties falling asleep or maintaining sleep continuity, the second aspect (sleep disturbances) refers to sleep interruptions (like waking up in the middle of the night, earlier than intended or to use the bathroom, due to breathing difficulties, coughing or snoring, or feeling cold or hot, having nightmares, feeling pain, among other reasons). These data are in line with the results described in the systematic review by Kelly et al. (12), who have found that consistent evidence associating CLBP with: sleep disorders; reduced sleep time and sleep quality; increased sleep latency; lower sleep efficiency (ratio of hours slept as compared to hours spent in bed); and daytime dysfunction.

Results from the RMDQ indicated moderate perceived functional disability (mean score, $16.71 \pm$ 4.16). However, most respondents (49.01\%) continued as active workers, which suggests that, many patients continue their work activities, despite functional losses. This may further contribute to the maintenance of the "pain-strain" cycle.

Some studies, such as the ones conducted by MARIN et. al. (24) and O'DONOGHUE et al. (24), associate sleep quality with the intensity of pain perceived by patients and measured with the Visual Analog Scale (VAS). Conversely, Alsaadi et al. (17) have found that pain intensity was weakly associated with sleep disturbances, and suggested that other factors besides pain may interfere with sleep. In this study we chose to use a tool that measures perceived disability, because it seems to be a more stable measure and because it has been used in many other studies conducted with people with CLBP (25-31).

Our results indicate a positive association between sleep quality and functional disability. Higher levels of disability are associated with poorer sleep quality. Our results also suggest that, because the association between functional disability and sleep disturbances is weak, other factors may be associated with poor sleep quality. Moreover, changes in sleep quality may have a multicausal origin, which requires further studies on the cause of these disorders. Moreover, the size of the sample and the inexistence of a control group are recognized as limitations of this study. 
It is important that health care providers from different disciplines participate in the treatment of CLBP and associated conditions, because they can highly affect patients' quality of life. Thus, we suggest the provision of a multidisciplinary care service to patients with CLBP, as well as the contemplation of other aspects, such as sleep quality, in order to optimize the results and provide patients with comprehensive care.

\section{Conclusion}

We have found a high prevalence of sleep disorders among patients with CLBP, and a weak association with the level of perceived disability. It is important to conduct further studies on the relationship between these factors and sleep quality. Moreover, there is a need for a multidisciplinary approach in the treatment of CLBP, in order to treat sleep disorders and improve patients' quality of life.

\section{References}

1. Gore M, Sadosky A, Stacey BR, Tai K-S, Leslie D. The burden of chronic low back pain: clinical comorbidities, treatment patterns, and health care costs in usual care settings. Spine. 2012 May 15;37(11):E668-E77. PubMed PMID: WOS:000303942500005.

2. Noriega-Elío M, Soto AB, Martínez OS, Ramírez IM, Navarro MP, Flores CC. La polémica sobre lãs lumbalgias y su relación com el trabajo: estudio restropetivo em trabajadores com invalidez. Cad Saude Pública. 2005;21:887-97.

3. Dagenais S, Caro J, Haldeman S. A systematic review of low back pain cost of illness studies in the United States and internationally. Spine J. 2008 Jan-Feb;8(1):8-20. PubMed PMID: 18164449. Epub 2008/01/01. eng.

4. Rudy TE, Weiner DK, Lieber SJ, Slaboda J, Boston JR. The impact of chronic low back pain on older adults: a comparative study of patients and controls. Pain. 2007 Oct;131(3):293-301. PubMed PMID: 17317008. Pubmed Central PMCID: PMC2065872. Epub 2007/02/24. eng.
5. Tang NKY, Wright KJ, Salkovskis PM. Prevalence and correlates of clinical insomnia co-occurring with chronic back pain. J Sleep Res. 2007 Mar;16(1):8595. PubMed PMID: WOS:000244277500011.

6. Marty M, Rozenberg S, Duplan B, Thomas P, Duquesnoy B, Allaert F, et al. Quality of sleep in patients with chronic low back pain: a case-control study. Eur Spine J. 2008 Jun;17(6):839-44. PubMed PMID: WOS:000256755200010.

7. Purushothaman B, Lingutla K, Singh A, Bhatia C, Pollock R, Krishna M. Do patients with chronic back pain sleep well? Spine. 2008;8:1S-19S.

8. Van de Water ATM, Eadie J, Hurley DA. Investigation of sleep disturbance in chronic low back pain: An age- and gender-matched case-control study over a 7-night period. Man Ther. 2011 Dec;16(6):550-6. PubMed PMID: WOS:000297294000005.

9. Haack M, Mullington JM. Sustained sleep restriction reduces emotional and physical well-being. Pain. 2005 Dec 15;119(1-3):56-64. PubMed PMID: 16297554. Epub 2005/11/22. eng.

10. Yaggi HK, Araujo AB, McKinlay JB. Sleep duration as a risk factor for the development of type 2 diabetes. Diabetes care. 2006 Mar;29(3):657-61. PubMed PMID: 16505522. Epub 2006/03/01. eng.

11. Lautenbacher S, Kundermann B, Krieg JC. Sleep deprivation and pain perception. Sleep Med Rev. 2006 Oct;10(5):357-69. PubMed PMID: WOS:000240950900006.

12. Kelly GA, Blake C, Power CK, O'Keeffe D, Fullen BM. The association between chronic low back pain and sleep: a systematic review. Clin J Pain. 2011 Feb;27(2):16981. PubMed PMID: WOS:000285993200012.

13. Ustinov Y, Lichstein KL, Wal GSV, Taylor DJ, Riedel BW, Bush AJ. Association between report of insomnia and daytime functioning. Sleep Med. 2010 Jan;11(1):65-8.

14. O'Brien EM, Staud RM, Atchison JW, Gremillion HA, Waxenberg LB, Robinson ME. Negative mood mediates the relationship between poor sleep and increased pain in chronic pain patients. Sleep. 2008;31:A300-A. PubMed PMID: WOS:000255419001342. 
15. Smith MT, Haythornthwaite JA. How do sleep disturbance and chronic pain inter-relate? Insights from the longitudinal and cognitive-behavioral clinical trials literature. Sleep Med Rev. 2004 Apr;8(2):119-32.

16. Heffner KL, France CR, Trost Z, Ng HM, Pigeon WR. Chronic low back pain, sleep disturbance, and Interleukin-6. Clin J Pain. 2011 Jan;27(1):35-41. PubMed PMID: WOS:000285289200005.

17. Alsaadi SM, McAuley JH, Hush JM, Maher CG. Prevalence of sleep disturbance in patients with low back pain (vol 20, pg 737, 2011). Eur Spine J. 2012 Mar;21(3):55460. PubMed PMID: WOS:000301441100024.

18. Eadie J, van de Water AT, Lonsdale C, Tully MA, van Mechelen W, Boreham CA, et al. Physiotherapy for sleep disturbance in people with chronic low back pain: results of a feasibility randomized controlled trial. Arch Phys Med Rehabil. 2013 May 2. PubMed PMID: 23643716. Epub 2013/05/07. Eng.

19. O'Donoghue GM, Fox N, Heneghan C, Hurley DA. Objective and subjective assessment of sleep in chronic low back pain patients compared with healthy age and gender matched controls: a pilot study. BMC Musculoskelet Disord. 2009;10:122. PubMed PMID: 19799778. Pubmed Central PMCID: PMC2765952. Epub 2009/10/06. eng.

20. Nusbaum L, Natour J, Ferraz MB, Goldenberg J. Translation, adaptation and validation of the Roland-Morris questionnaire - Brazil Roland-Morris. Braz J Med Biolog Res. 2001;34:203-10.

21. Schiphorst Preuper HR, Reneman MF, Boonstra AM, Dijkstra PU, Versteegen GJ, Geertzen JHB. The relationship between psychosocial distress and disability assessed by the Symptom Checklist-90-revised and Roland Morris Disability Questionnaire in patients with chronic low back pain. Spine J. 2007 Sep;7(5):525-30.

22. Bertolazi AN, Fagondes SC, Hoff LS, Dartora EG, da Silva Miozzo IC, de Barba MEF, et al. Validation of the Brazilian Portuguese version of the Pittsburgh Sleep Quality Index. Sleep Med. 2011 Jan;12(1):70-5.

23. Hulley SB, Cummings SR, Browner WS, Grady D, Newman TB. Delineando a pesquisa clínica: uma abordagem epidemiológica. $2^{\text {th }}$ ed. Artmed: Porto Alegre; 2003.
24. Marin R, Cyhan T, Miklos W. Sleep disturbance in patients with chronic low back pain. Amer J Phys Med Rehabil. 2006 May;85(5):430-5. PubMed PMID: WOS:000237161300003.

25. Freitas CD, Greve JMDA. Estudo comparativo entre exercícios com dinamômetro isocinético e bola terapêutica na lombalgia crônica de origem mecânica. Fisioter Pesq. 2008;15:380-6.

26. Pereira NT, Ferreira LAB, Pereira WM. Efetividade de exercícios de estabilização segmentar sobre a dor lombar crônica mecânico-postural. Fisioter Mov. 2010;23:605-14.

27. Morris J, Watson PJ. Investigating decisions to absent from work with low back pain: a study combining patient and GP factors. Eur J Pain. 2011 3//;15(3):278-85.

28. Katz N, Borenstein DG, Birbara C, Bramson C, Nemeth MA, Smith MD, et al. Efficacy and safety of tanezumab in the treatment of chronic low back pain. Pain. 2011 Oct;152(10):2248-58.

29. Lamb SE, Lall R, Hansen Z, Withers EJ, Griffiths FE, Szczepura A, et al. Design considerations in a clinical trial of a cognitive behavioural intervention for the management of low back pain in primary care: Back Skills Training Trial. BMC Musculoskelet Disord. 2007 Feb 22;8. PubMed PMID: WOS:000245387300001.

30. Vas J, Aranda JM, Modesto M, Benítez-Parejo N, Herrera A, Martínez-Barquín DM, et al. Acupuncture in patients with acute low back pain: a multicentre randomised controlled clinical trial. Pain. 2012 Sep; 153(9):1883-9.

31. Lewis S, Holmes P, Woby S, Hindle J, Fowler N. The relationships between measures of stature recovery, muscle activity and psychological factors in patients with chronic low back pain. Man Ther. 2012 Feb;17(1):27-33.

Received: 06/07/2013 Recebido: 07/06/2013

Approved: 06/11/2015 Aprovado: 11/06/2015 